Research Article

\title{
Prediction of Cutting Conditions in Turning AZ61 and Parameters Optimization Using Regression Analysis and Artificial Neural Network
}

\author{
Nabeel H. Alharthi, ${ }^{1}$ Sedat Bingol, ${ }^{2}$ Adel T. Abbas $\mathbb{D}^{1},{ }^{1}$ Adham E. Ragab $\mathbb{D},{ }^{3}$ \\ Mohamed F. Aly $\mathbb{D}^{4},{ }^{4}$ and Hamad F. Alharbi $\mathbb{D D}^{1}$ \\ ${ }^{1}$ Department of Mechanical Engineering, College of Engineering, King Saud University, P.O. Box 800, Riyadh 11421, Saudi Arabia \\ ${ }^{2}$ Department of Mechanical Engineering, Dicle University, Diyarbakir 21280, Turkey \\ ${ }^{3}$ Department of Industrial Engineering, College of Engineering, King Saud University, P.O. Box 800, Riyadh 11421, Saudi Arabia \\ ${ }^{4}$ Department of Mechanical Engineering, School of Sciences and Engineering, American University in Cairo, AUC Avenue, P.O. \\ Box 11835, New Cairo, Egypt
}

Correspondence should be addressed to Adel T. Abbas; atabbas1954@yahoo.com

Received 6 November 2017; Revised 18 December 2017; Accepted 21 December 2017; Published 13 February 2018

Academic Editor: Fernando Lusquiños

Copyright $\odot 2018$ Nabeel H. Alharthi et al. This is an open access article distributed under the Creative Commons Attribution License, which permits unrestricted use, distribution, and reproduction in any medium, provided the original work is properly cited.

\begin{abstract}
All manufacturing engineers are faced with a lot of difficulties and high expenses associated with grinding processes of AZ61. For that reason, manufacturing engineers waste a lot of time and effort trying to reach the required surface roughness values according to the design drawing during the turning process. In this paper, an artificial neural network (ANN) modeling is used to estimate and optimize the surface roughness $\left(R_{a}\right)$ value in cutting conditions of AZ61 magnesium alloy. A number of ANN models were developed and evaluated to obtain the most successful one. In addition to ANN models, traditional regression analysis was also used to build a mathematical model representing the equation required to obtain the surface roughness. Predictions from the model were examined against experimental data and then compared to the ANN model predictions using different performance criteria such as the mean absolute error, mean square error, and coefficient of determination.
\end{abstract}

\section{Introduction}

Magnesium alloys are often used in many industrial applications such as the manufacturing of several components used in the aerospace and modern automobiles industry. Also, magnesium block engines have been widely used in some high-performance vehicles. In those applications, the final surface roughness of machined components is playing a major factor in the acceptance of those parts.

Many researchers have investigated the optimization of cutting parameters for the prediction of surface roughness as a key performance measure. Asiltürk used ANN (artificial neural network) and MRM (multiregression models) to predict the surface roughness of steel AISI 1040. They developed their own models and used ANN to optimize the cutting parameters formulating the surface roughness as objective function. They used cutting speed, feed rate, depth of cut, and nose radius as optimized parameters. Surface roughness is characterized by the mean $\left(R_{a}\right)$ and total $\left(R_{t}\right)$ values of the recorded roughness at different locations on the produced surface. They conducted many experiments, each with a different set of the cutting parameters, and the corresponding $R_{a}$ and $R_{t}$ values were reported. Obtained results were then used to train an ANN model. Mean squared error of approximately $0.003 \%$ was achieved which outperforms error rates reported in the early literature and are claimed to be suitable for robust prediction of the surface roughness in industrial settings [1].

Another approach can be found in the work of Mokhtariet Homami et al. [2], and they employed a design of experiment 
(DOE) technique based on a full factorial design to determine the number of experiment and the corresponding parameters. They represented their results in a statistical analysis, and they used ANN to model the system. Optimization was done using genetic algorithm (GA). The conclusion of their work was that the main factors affecting the flank wear and the produced surface roughness are the feed rate, nose radius, and approach angle, while the cutting speed had the major effect on flank wear. Optimized values of the cutting conditions were attained and showed a significant reduction in the surface roughness values.

Jafarian et al. [3] used GA and particle swarm optimization (PSO) techniques to determine optimal cutting parameters in turning operations with a multiobjective optimization aiming to minimize surface roughness and cutting forces and maximize tool life. They discussed their results claiming that training ANN using GA gave superior results than those reported in the literature with high accuracy and gives the flexibility of analyzing the effect of each parameter separately on the output.

The PSO technique was also utilized in the work of Karpat and Özel [4], and they used the Pareto optimal frontier to select optimized parameters to maximize material removal rate (MRR) without affecting the induced stresses or the final surface finish of the produced components. They obtained good results making use of dynamic-neighborhood PSO approach in solving complex turning optimization problems.

A different approach was utilized in the work of Natarajan et al. [5] to test the reliability of ANN in the prediction of surface roughness values when machining Brass C26000 material in dry cutting condition on a CNC turning machine. Surface roughness has been measured and compared to the experimental data and concluded that ANN can be implemented reliably and accurately to predict surface roughness in turning operations of Brass C26000 material.

The applicability of radial base function ( $R B F)$ neural networks was investigated in the work of Pontes et al. [6] to predict surface roughness in turning processes of SAE 52100 hardened steel. Networks were trained using different sets. They considered several design variables and found that ANN models were capable of providing accurate estimates of surface roughness values in an affordable way.

The turning of Ti-6Al-4V titanium alloy was investigated in the work of Sangwan et al. [7] to minimize surface roughness using ANN-GA approach. A feed forward neural network was proposed for training and testing of the neural network model. The predicted results were found to be in good agreement with the obtained experimental results.

A comparison between linear regression models and ANN approach has been studied in the work of Acayaba and Escalona [8]. A target of saving cost, effort, and machining time leads to the necessity of predicting surface roughness prior to performing machining operations. They used experimental data to validate their claim and found that using ANN outperforms linear modeling. Instead of using GA like other researchers previously listed, this research employed a simulated annealing (SA) optimization algorithm to optimize cutting parameters for minimizing surface roughness. Results show similar findings as reported previously with no major significant improvement.
A more concise investigation focusing only on the three major cutting parameters influencing the surface roughness was presented in the work of Bajić et al. [9]. Cutting speed, feed rate, and depth of cut are optimized using regression analysis and ANN. Results obtained show no superiority of one approach over the other, and both gave a good prediction of the surface roughness.

A new approach that integrates artificial intelligence (AI) with ANN and GA has been introduced by Gupta et al. [10], and the paper illustrates the impact of using AI on the quality and type of results obtained for the surface roughness prediction. They analyzed the experimental data using support vector regression (SVR) defining the tool wear and power required as output parameters.

Grade-H high-strength steel had its share in the investigation for better surface quality studied by Abbas et al. [11] in their work. They emphasized that the key factors for the manufacturing of parts produced using Grade- $\mathrm{H}$ highstrength steel are parts accuracy and surface roughness MRR. Identifying the final surface roughness of produced parts prior to machining is crucial to ensure that those parts will not be rejected. The rejection of these parts at any processing stage will represent huge problems to any factory because the processing and raw material of these parts are very expensive. ANN was used in this work to determine the optimized cutting parameters to ensure minimum surface roughness during the turning operations.

As a continuation of their work, Abbas et al. [12] investigated the turning of high-strength steel focusing on three main cutting parameters: cutting speed, feed rate, and depth of cut. Their results included a Pareto frontier between surface roughness and machining time of finished components made from high-strength steel using the ANN model that was later used to determine the optimum cutting conditions. This study showed the feasibility of integrating optimization algorithms with computer-aided manufacturing CAM systems using Matlab.

A quantitative approach to evaluate the cutting process and its stability was demonstrated in the work of Yamane et al. [13], and they used the turning operation as a base for their study aiming at identifying the machining system deviation from a perfect process. Such a deviation can be identified by monitoring the machined surface and comparing it with the cutter profile. Adhesion and builtup edge produced during machining operation can then be easily noticed and monitored. Excessive vibration and the accuracy of spindle rotation can also be recorded and is a good indication of system instability and related directly to the quality of parts produced. Their conclusion was that the proposed method can be successfully implemented to evaluate turning operations.

The influence of the type of inserts used in the machining process on the quality of the surface produced was investigated in the work of D'Addona and Raykar [14]. They compared wiper inserts to conventional ones in the turning operation of oil hardened nonshrinking steel used in the manufacture of strain gauges and measuring instruments. Surface roughness was a major factor in this study as it is a very important aspect in the performance of those devices. 
They used analysis of variance (ANOVA) and analysis of means (AOM) plots to evaluate their results.

$\mathrm{Pu}$ et al. [15] reported that magnesium alloys are gaining a lot of intension from researchers in the literature due to their advanced properties over conventional materials used in the automotive industry as well as medical applications such as biodegradable implants. One of the major factors looked at in machining of this alloy is the surface integrity. $\mathrm{Pu}$ et al. [15] investigated the effect of machining AZ31B Mg alloy under dry conditions as well as using liquid nitrogen as a lubricant. They concluded that using cryogenic machining with large nose radii improved several material performance criteria such as surface finish and grain size refinement.

Increasing productivity and maximizing material removal rate (MMR) have been also investigated for the machining of magnesium alloys. Using very high cutting speeds has its drawbacks and has been analyzed by Tomac et al. [16] in their work. They concluded that using speeds in excess of $600 \mathrm{~m} / \mathrm{min}$ will result in buildup edge on the flank face of the cutting tool. They supported their argument with microstructure pictures of tool inserts as well as the machined surface of three different $\mathrm{Mg}$-Al-Zn alloys.

Different coating materials have been used in industry to reduce the builtup edge effect appearing on the tool flank face during turning operations of magnesium alloys at high speeds. Tönshoff and Winkler [17] reported the different interactions happening between the cutting tool inserts, the coating, and the workpiece materials in turning of AZ91 HP at very high speeds ranging between 900 and $2400 \mathrm{~m} / \mathrm{min}$. They concluded that cutting tools with polycrystalline diamond (PCD) inserts can significantly reduce the cutting forces and hence the frictions at the tool-workpiece interface.

The optimization of cutting parameters is another venue pursued by researchers to improve surface quality of machined magnesium alloys. Wojtowicz et al. [18] studied the effect of changing cutting parameters on the turning of AZ91 HP. Parameters explored include cutting speed, feed rate, depth of cut, and tool nose radius. Surface integrity and increasing fatigue life were the major optimized parameters of the machined components, and other reported parameters include microstructure, grain size and residual stresses improve fatigue life. They also supported the argument provided by Tönshoff and Winkler [17] regarding the superior performance of PCD coating tool inserts at high cutting speeds and feed rates.

In this paper, an ANN model has been employed to estimate and optimize the produced surface roughness of AZ61 material during turning operations. This method proves to be more efficient and provided the manufacturing engineers with a good tool to be utilized to effectively predict the quality of the surface produced in an economical and time saving manner. Thus this eliminates the possibility of part rejection due to manufacturing process errors that costs the factory time and money and wasted raw material.

\section{Materials and Methods}

Table 1 presents the chemical composition of magnesium alloy AZ61 which contains zinc and aluminum with 1 and 6 percent content, respectively. The microstructure of the composition is analyzed at the previously mentioned aluminum concentration, and the phase diagram shows a magnesium-rich phase interacting with an $\mathrm{Al}_{12} \mathrm{Mg}_{17}$ composite. Zinc along with other traces is found to have no effect on the alloy microstructure.

The machining of test specimens is done using Emco mill concept $45 \mathrm{CNC}$ turning machine equipped with Sinumeric $840-\mathrm{D}$. The diameter of the workpiece is equal to $40 \mathrm{~mm}$ with a length of $100 \mathrm{~mm}$. Tool holder specification is SVJCL2020K16, while the insert is VCGT160404 FN-ALU. The cutting edge angle, nose radius, and clearance angle are set at $35^{\circ}, 0.4 \mathrm{~mm}$, and $5^{\circ}$, respectively. All experiments were conducted in wet conditions while the cutting parameters are controlled via CNC part program. The surface roughness tester TESA Rugosurf $90-\mathrm{G}$ is used to evaluate the produced surface roughness. A sketch of the test specimen is shown in Figure 1. The test plan was implemented through 64 turning runs. These runs were divided into 16 groups. Each of four groups was subjected to one common cutting speed (125, 150,175 , and $200 \mathrm{~m} / \mathrm{min}$ ). Each group was machined using four levels of cutting depth $(0.30,0.60,0.90$, and $1.12 \mathrm{~mm})$. Each depth was processed using feed rate having four levels $(0.05,0.010,0.15$, and $0.20 \mathrm{~mm} / \mathrm{rev})$. Full listing of all samples and the resulting measured surface roughness are provided in Appendix A.

Multivariable regression analysis was used to build a mathematical model relating the process outcome (surface roughness $R_{a}$ ) with the three studied input parameters (cutting speed $(V)$, depth of cut $(d)$, and feed rate (fr)). 56 experiments were conducted that cover the input parameter range described previously. Eight extra experimental runs were carried out to be used in testing both the regression and ANN models.

Regression was conducted using Minitab 17 software with stepwise technique to eliminate the insignificant terms from the model. The model was fitted in the form given by the following equation [19]:

$$
\begin{aligned}
R_{a}= & \beta_{o}+\sum_{i=1}^{k} \beta_{i} X_{i}+\sum_{i=1}^{k} \beta_{i i} X_{i}^{2}+\sum \sum_{i<j} \beta_{i j} X_{i} X_{j} \\
& +\sum_{i<j<k} \beta_{i j k} X_{i} X_{j} X_{k}+\sum \sum_{i \neq j} \beta_{i i j} X_{i}^{2} X_{j}+\varepsilon_{i},
\end{aligned}
$$

where $\beta_{o}$ is the constant term, $\beta_{i}$ represents the linear effects, $\beta_{i i}$ represents the pure quadratic effects, $\beta_{i j}$ represents the second level interaction effects, $\beta_{i j k}$ the third level interaction effects, $\beta_{i i j}$ represents the effect of interaction between linear and quadratic terms, and $\varepsilon_{i}$ represents the error in predicting experimental surface roughness. The material removal rate (MRR) was calculated using (2) for each run. Desirability function approach was used to maximize MRR maintaining $R_{a}$ below 0.4 as a maximum limit for the surface roughness value:

$$
\mathrm{MRR}=1000 V * \mathrm{fr} * d,
$$

where MRR is the volume removed per unit time $\left(\mathrm{mm}^{3} / \mathrm{min}\right.$.), $V$ is the cutting speed $(\mathrm{m} / \mathrm{min}$.), fr is the feed 
TABLE 1: AZ61 magnesium alloy chemical composition.

\begin{tabular}{lccccccc}
\hline Element & Aluminium & Zinc & Copper & Silicon & Iron & Nickel & Magnesium \\
\hline \% by mass & 5.95 & 0.95 & $<0.03$ & $<0.01$ & $<0.01$ & $<0.005$ & Balance \\
\hline
\end{tabular}

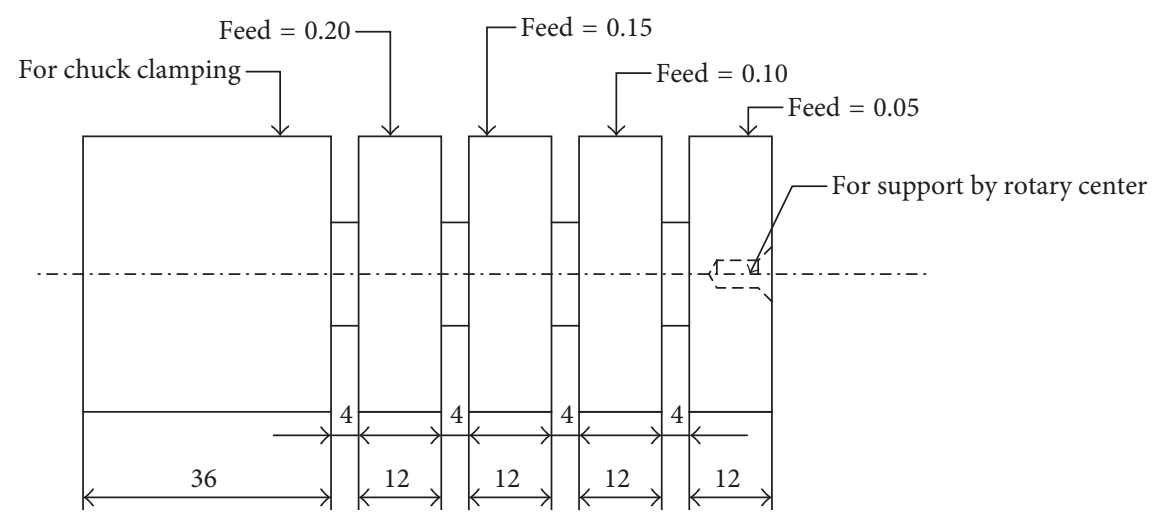

FIGURE 1: Working drawing of the test workpiece.

rate $(\mathrm{mm} / \mathrm{rev})$, and $d$ is the depth of cut $(\mathrm{mm})$. Multivariable regression analysis was used to build a mathematical model relating the process outcome (surface roughness $R_{a}$ ) with the three studied input parameters (cutting speed $(V)$, depth of cut $(d)$, and feed rate (fr)). 56 experiments were conducted that cover the input parameters range described previously. Eight extra experimental runs were carried out to be used in testing both the regression and ANN models.

\section{Results and Discussions}

The regression-fitted mathematical model is given by (3). Box-Cox transformation was used to normalize the residuals with $\lambda=0$ (natural $\log$ ) for $R_{a}$. Anderson-Darling test was conducted to check the normality of residuals with a result of $p$ value $=0.885>0.05$. The null hypothesis of such a test is that the data are normal, and a $p$ value $<0.05$ proves nonnormality.

Determination coefficient $\left(R^{2}\right)$, mean square error (MSE), and mean absolute error (MAE) were calculated to be $0.975,0.02$, and 0.12 , respectively. Figure 2 shows a scatter plot for the predicted $R_{a}$ versus measured $R_{a}$. It is clear from the figure that the relation between them is very close to linear with calculated $R^{2}$ equals 0.97 .

$$
\ln \left(R_{a}\right)=-2.6420+0.1874 d+16.516 \mathrm{fr} .
$$

Desirability function approach was used to estimate the values of studied process parameters that maximize the MRR keeping $R_{a}$ at levels not exceeding a practical value of $0.4 \mu \mathrm{m}$. The optimization plot, illustrated in Figure 3, shows that an optimum MRR of $13,928 \mathrm{~mm}^{3} / \mathrm{min}$ with $R_{a}=0.4 \mu \mathrm{m}$ is obtained at cutting speed $200 \mathrm{~m} / \mathrm{min}$., depth of cut $1.12 \mathrm{~mm}$, and feed rate $0.09 \mathrm{~mm} / \mathrm{rev}$.

ANN modeling was used to predict the surface roughness of AZ61 magnesium alloy. The three input parameters cutting speed $(V)$, depth of cut $(d)$, and feed rate (fr) were

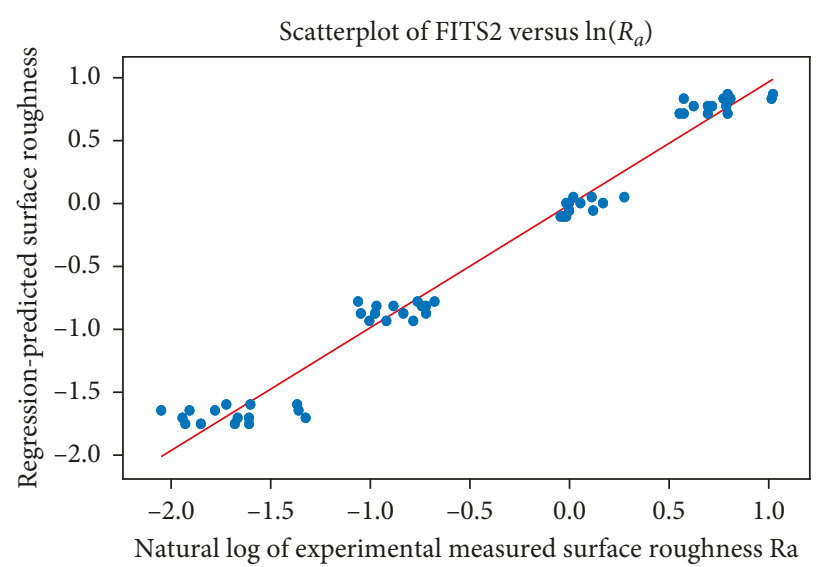

FIgURE 2: Experimental readings versus regression model predictions.

taken into account to predict the surface roughness as an output parameter. The data were taken from the experimental result. The transfer function was selected as a TanhAxon. The data were divided in two parts as training and test data. $80 \%$ of data were used for training stage while the left $20 \%$ of data were used for test stage to understand the performance of the developed ANN model. The best ANN model predicting the $R_{a}$ value between developed trial models was obtained according to the values of $R^{2}$ and MSE. Figure 4 gives the experimental and ANN-predicted results. It can be seen from the figure that a good agreement was obtained between experimental and ANN-predicted results. It is also seen from Figure 5 that the value of $R^{2}$ is 0.9629 for experimental surface $R_{a}$ and ANN-predicted surface $R_{a}$, while $R^{2}$ is 0.9931 for experimental MRR and ANN-predicted MRR in Figure 6. 


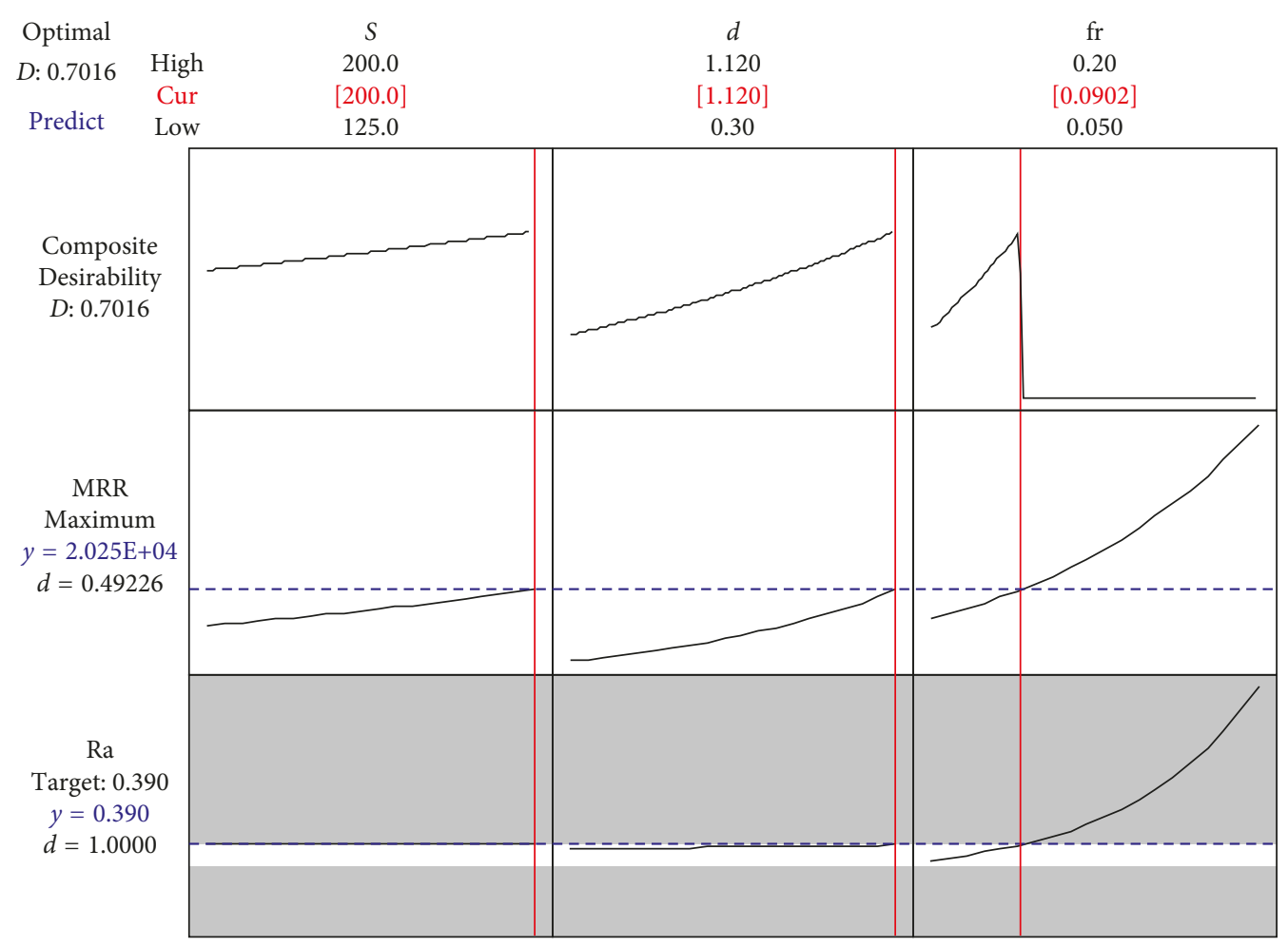

Figure 3: Optimization plot for $R_{a}$ and MRR.

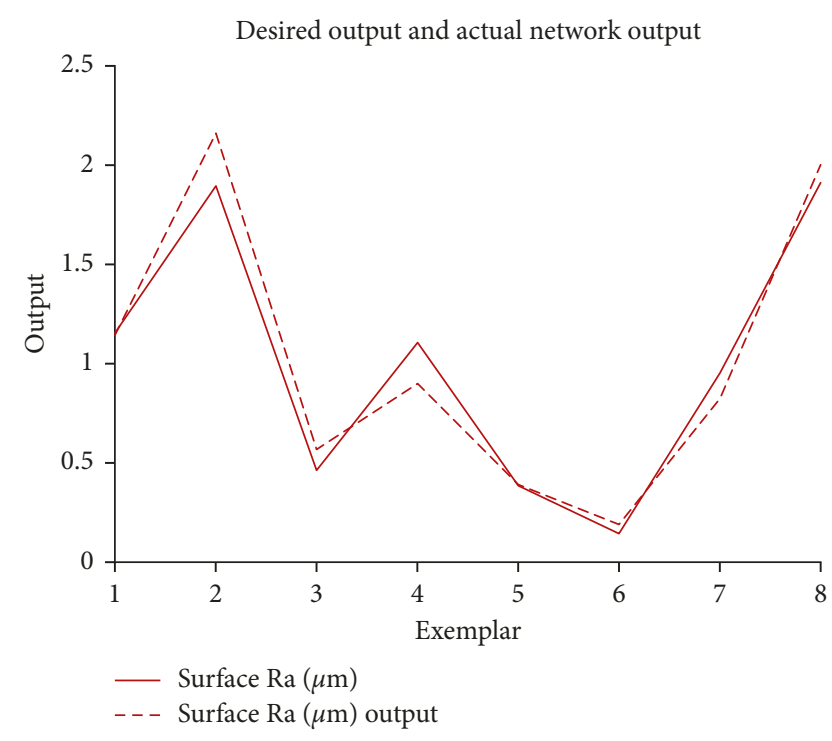

FIgURE 4: Desired output and actual network output.

Predictability of both regression and ANN models were compared using eight extra experimental cases that were not included in the modeling phase. Table 2 illustrates the results of this comparison. Figures 4-6 and Table 2 clearly show the good agreement between the results. From the table, both ANN and regression-predicted $R_{a}$ and MRR values can be acceptable when they are compared with experimental results.

Feed rate has a direct impact on product surface finish. Although increasing feed rate can result in

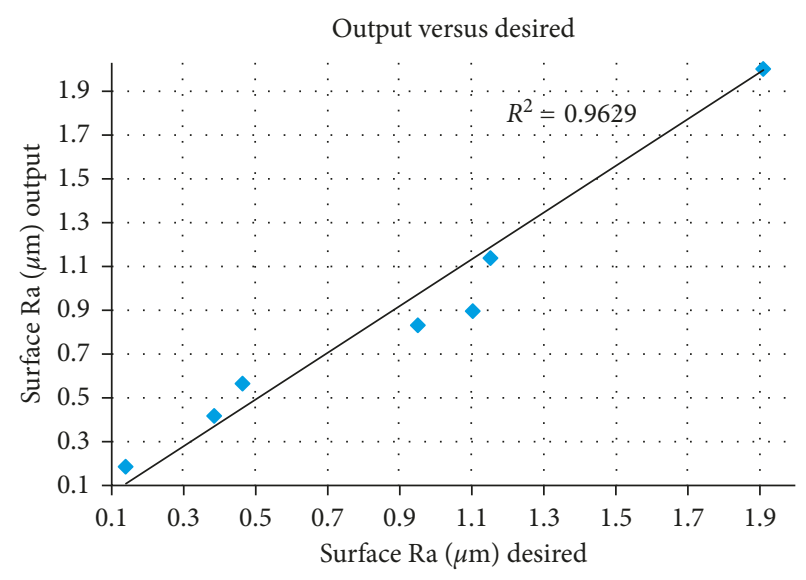

FIgURE 5: Comparison between ANN predicted and desired output for $R_{a}$.

a significant increase in the material removal rate (MMR) and increase productivity, it will also increase cutting forces resulting in higher tool-workpiece friction associated with poor surface finish. Horizontal markings as well as vertical ones in surface roughness profile can be detected when examining the surface profile produced using high feed rates. MRR and surface roughness are two contradicting objectives in determining an optimized value for the feed rate. Optimization algorithms are often used to come up with optimized cutting parameters for different machining processes. Figure 7 represents an optical microscopy view of machined surface, while Figure 8 shows the surface roughness profile produced by 


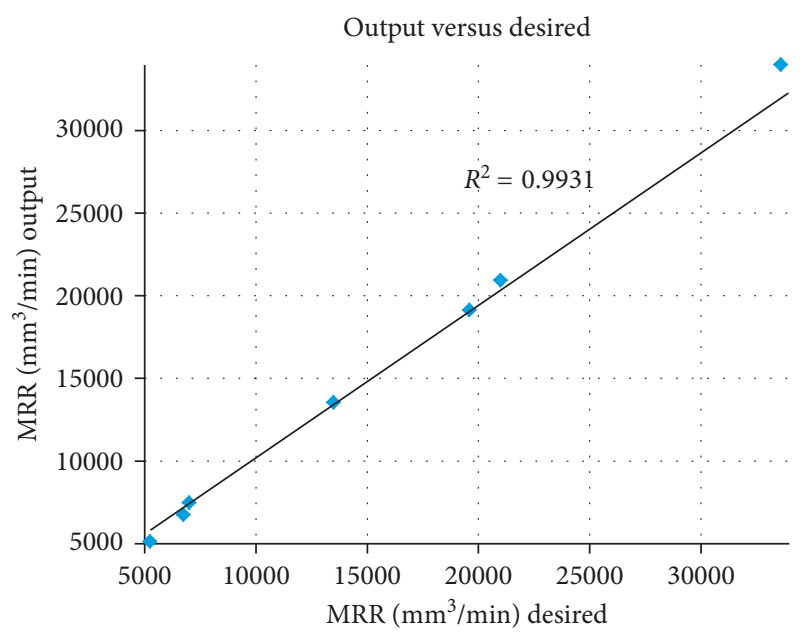

Figure 6: Comparison between ANN predicted and desired output for MRR.

TABle 2: Comparison between the regression model and ANN predictions.

\begin{tabular}{|c|c|c|c|c|c|c|c|}
\hline \multicolumn{3}{|c|}{ Machining parameters } & \multirow{2}{*}{ Measured $R_{a}(\mu \mathrm{m})$} & \multicolumn{2}{|c|}{ Regression model } & \multicolumn{2}{|c|}{ ANN } \\
\hline Speed & Depth & Feed & & Predicted $R_{a}$ & Residual & Predicted $R_{a}$ & Residual \\
\hline 125 & 1.12 & 0.15 & 1.154 & 1.05 & 0.11 & 1.14 & 0.01 \\
\hline 200 & 1.12 & 0.2 & 1.896 & 2.39 & -0.49 & 2.16 & -0.26 \\
\hline 175 & 1.12 & 0.1 & 0.464 & 0.46 & 0.01 & 0.57 & -0.11 \\
\hline 150 & 0.6 & 0.15 & 1.1058 & 0.95 & 0.16 & 0.90 & 0.21 \\
\hline 175 & 0.3 & 0.1 & 0.386 & 0.39 & -0.01 & 0.39 & -0.01 \\
\hline 125 & 1.12 & 0.05 & 0.144 & 0.20 & -0.06 & 0.19 & -0.05 \\
\hline 150 & 0.3 & 0.15 & 0.954 & 0.90 & 0.06 & 0.83 & 0.12 \\
\hline 150 & 1.12 & 0.2 & 1.911 & 2.39 & -0.48 & 2.00 & -0.09 \\
\hline
\end{tabular}

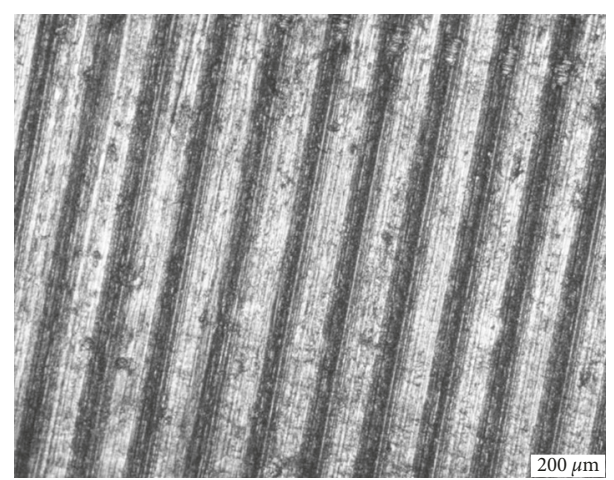

Figure 7: Optical microscopy for machined surface with $V=125 \mathrm{~m} / \mathrm{min}, d=0.30 \mathrm{~mm}$, and $\mathrm{fr}=0.20 \mathrm{~mm} / \mathrm{rev}$.

the surface roughness tester under the following cutting conditions: a speed of $125 \mathrm{~m} / \mathrm{min}$, a depth of cut of $0.3 \mathrm{~mm}$, and a feed rate of $0.20 \mathrm{~mm} / \mathrm{rev}$. Another set of views and graph is also provided in Figures 9 and 10 for different cutting conditions summarized as follows: a cutting speed of $125 \mathrm{~m} / \mathrm{min}$, a depth of cut of $0.3 \mathrm{~mm}$, and a feed rate of $0.05 \mathrm{~mm} / \mathrm{rev}$. From those results, we can conclude that reducing feed rate will produce thinner surface roughness markings, and increasing the feed rate is associated with the presence of distant thick surface roughness markings.

\section{Conclusions}

Optimization and estimation of $R_{a}$ and MRR in cutting conditions of AZ61 magnesium alloy were realized by ANN modeling and regression analysis. The results of the developed ANN-predicted model and regression model were 


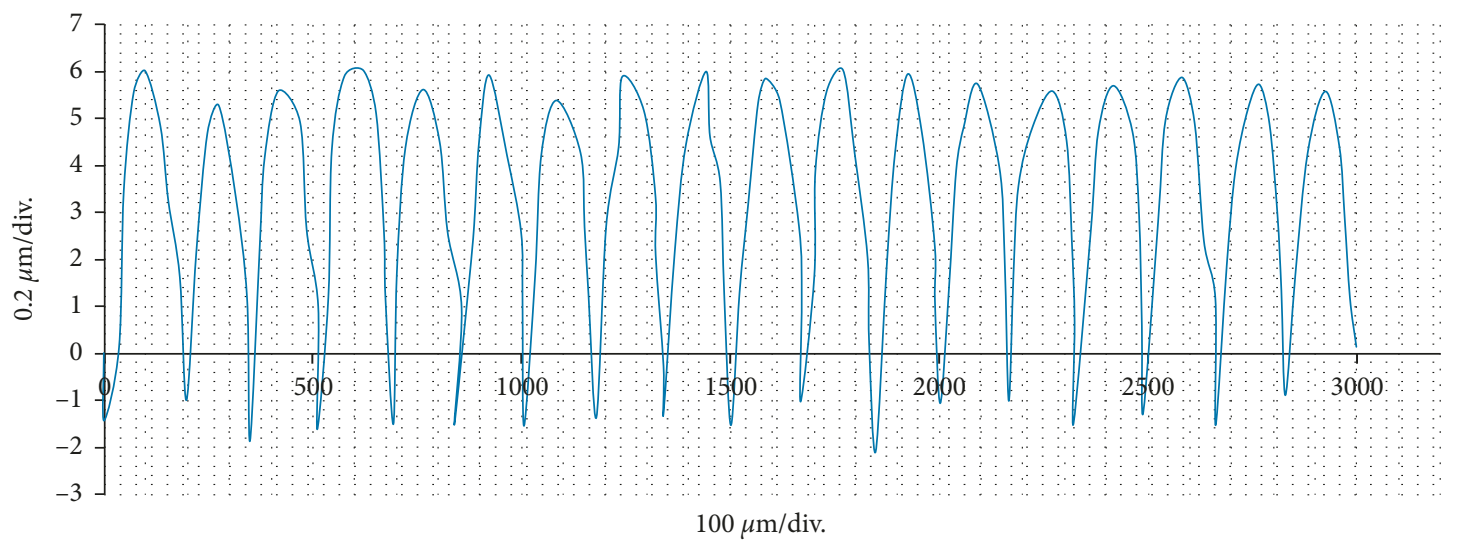

FIGURE 8: Profile of surface roughness graph by the surface roughness tester for machined surface with $V=125 \mathrm{~m} / \mathrm{min}, d=0.30 \mathrm{~mm}$, and $\mathrm{fr}=0.20 \mathrm{~mm} / \mathrm{rev}$.

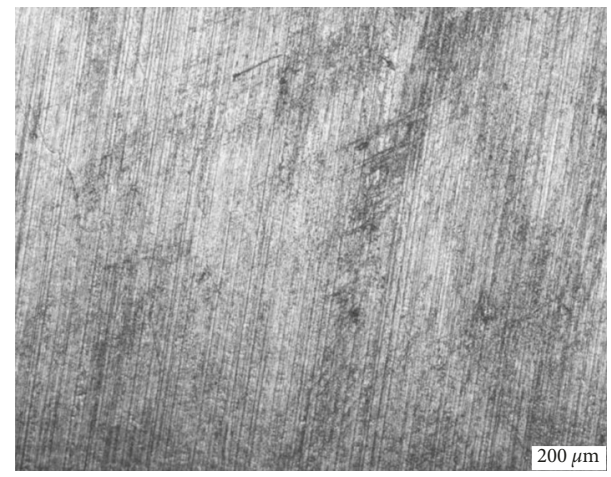

Figure 9: Optical microscopy for machined surface with $V=125 \mathrm{~m} / \mathrm{min}, d=0.30 \mathrm{~mm}$, and $\mathrm{fr}=0.05 \mathrm{~mm} / \mathrm{rev}$.

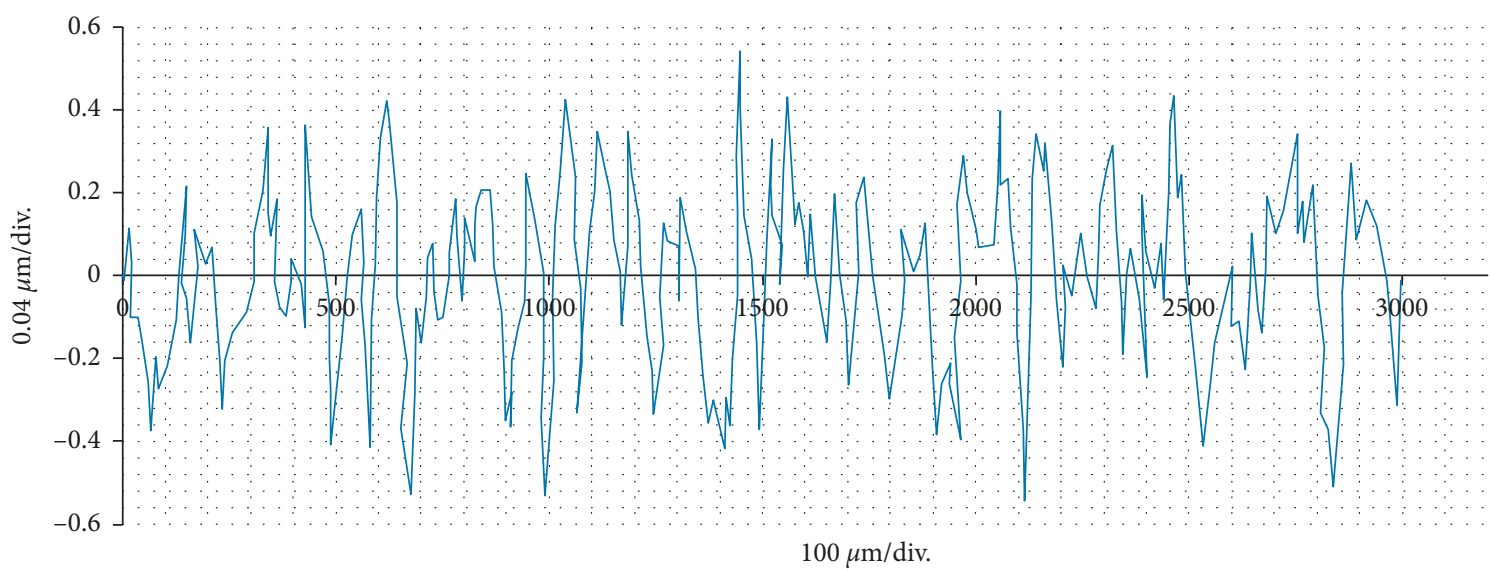

Figure 10: Profile of surface roughness graph by the surface roughness tester for machined surface with $V=125 \mathrm{~m} / \mathrm{min}, d=0.30 \mathrm{~mm}$, and $\mathrm{fr}=0.05 \mathrm{~mm} / \mathrm{rev}$.

compared with experimental results. The results showed that a good agreement was obtained for both developed ANNpredicted and regression analysis results. In addition, the compatibility between the developed ANN model and experimental results showed that ANN approach is an accurate method to estimate surface $R_{a}$ and MRR. Optical microscopy views and the corresponding surface roughness profile for different sets of cutting parameters were utilized on two machined surfaces to showcase the direct effect of increasing the feed rate on surface finish. A hypothetical analysis relating the higher surface roughness values associated with the increase in feed rate is reported.

\section{Appendix}

The listing of all samples and the resulting measured surface roughness are provided in Table 3. 
TABLE 3: Listing of four-level full factorial samples.

\begin{tabular}{|c|c|c|c|c|c|c|}
\hline Sample ID & Group & Cutting speed $(\mathrm{m} / \mathrm{min})$ & Depth of cut (mm) & Feed $(\mathrm{mm} / \mathrm{rev})$ & Surface $R_{a}(\mu \mathrm{m})$ & $\operatorname{MRR}\left(\mathrm{mm}^{3} / \mathrm{min}\right)$ \\
\hline 1 & \multirow{4}{*}{1} & 125 & 0.30 & 0.05 & 0.185 & 1875 \\
\hline 2 & & 125 & 0.30 & 0.10 & 0.457 & 3750 \\
\hline 3 & & 125 & 0.30 & 0.15 & 0.972 & 5625 \\
\hline 4 & & 125 & 0.30 & 0.20 & 1.779 & 7500 \\
\hline 5 & \multirow{4}{*}{2} & 125 & 0.60 & 0.05 & 0.188 & 3750 \\
\hline 6 & & 125 & 0.60 & 0.10 & 0.375 & 7500 \\
\hline 7 & & 125 & 0.60 & 0.15 & 0.998 & 11250 \\
\hline 8 & & 125 & 0.60 & 0.20 & 2.205 & 15000 \\
\hline 9 & \multirow{4}{*}{3} & 125 & 0.90 & 0.05 & 0.168 & 5625 \\
\hline 10 & & 125 & 0.90 & 0.10 & 0.378 & 11250 \\
\hline 11 & & 125 & 0.90 & 0.15 & 1.059 & 16875 \\
\hline 12 & & 125 & 0.90 & 0.20 & 2.254 & 22500 \\
\hline 13 & \multirow{4}{*}{4} & 125 & 1.12 & 0.05 & 0.144 & 7000 \\
\hline 14 & & 125 & 1.12 & 0.10 & 0.466 & 14000 \\
\hline 15 & & 125 & 1.12 & 0.15 & 1.154 & 21000 \\
\hline 16 & & 125 & 1.12 & 0.20 & 2.786 & 28000 \\
\hline 17 & \multirow{4}{*}{5} & 150 & 0.30 & 0.05 & 0.156 & 2250 \\
\hline 18 & & 150 & 0.30 & 0.10 & 0.365 & 4500 \\
\hline 19 & & 150 & 0.30 & 0.15 & 0.954 & 6750 \\
\hline 20 & & 150 & 0.30 & 0.20 & 1.737 & 9000 \\
\hline 21 & \multirow{4}{*}{6} & 150 & 0.60 & 0.05 & 0.143 & 4500 \\
\hline 22 & & 150 & 0.60 & 0.10 & 0.349 & 9000 \\
\hline 23 & & 150 & 0.60 & 0.15 & 1.1058 & 13500 \\
\hline 24 & & 150 & 0.60 & 0.20 & 1.866 & 18000 \\
\hline 25 & \multirow{4}{*}{7} & 150 & 0.90 & 0.05 & 0.128 & 6750 \\
\hline 26 & & 150 & 0.90 & 0.10 & 0.413 & 13500 \\
\hline 27 & & 150 & 0.90 & 0.15 & 0.999 & 20250 \\
\hline 28 & & 150 & 0.90 & 0.20 & 1.782 & 27000 \\
\hline 29 & \multirow{4}{*}{8} & 150 & 1.12 & 0.05 & 0.201 & 8400 \\
\hline 30 & & 150 & 1.12 & 0.10 & 0.508 & 16800 \\
\hline 31 & & 150 & 1.12 & 0.15 & 1.020 & 25200 \\
\hline 32 & & 150 & 1.12 & 0.20 & 1.911 & 33600 \\
\hline 33 & \multirow{4}{*}{9} & 175 & 0.30 & 0.05 & 0.199 & 2625 \\
\hline 34 & & 175 & 0.30 & 0.10 & 0.386 & 5250 \\
\hline 35 & & 175 & 0.30 & 0.15 & 0.982 & 7875 \\
\hline 36 & & 175 & 0.30 & 0.20 & 2.005 & 10500 \\
\hline 37 & \multirow{4}{*}{10} & 175 & 0.60 & 0.05 & 0.199 & 5250 \\
\hline 38 & & 175 & 0.60 & 0.10 & 0.432 & 10500 \\
\hline 39 & & 175 & 0.60 & 0.15 & 1.128 & 15750 \\
\hline 40 & & 175 & 0.60 & 0.20 & 2.054 & 21000 \\
\hline 41 & \multirow{4}{*}{11} & 175 & 0.90 & 0.05 & 0.256 & 7875 \\
\hline 42 & & 175 & 0.90 & 0.10 & 0.486 & 15750 \\
\hline 43 & & 175 & 0.90 & 0.15 & 1.187 & 23625 \\
\hline 44 & & 175 & 0.90 & 0.20 & 2.759 & 31500 \\
\hline 45 & \multirow{4}{*}{12} & 175 & 1.12 & 0.05 & 0.178 & 9800 \\
\hline 46 & & 175 & 1.12 & 0.10 & 0.464 & 19600 \\
\hline 47 & & 175 & 1.12 & 0.15 & 1.316 & 29400 \\
\hline 48 & & 175 & 1.12 & 0.20 & 2.214 & 39200 \\
\hline
\end{tabular}


TABle 3: Continued.

\begin{tabular}{|c|c|c|c|c|c|c|}
\hline Sample ID & Group & Cutting speed $(\mathrm{m} / \mathrm{min})$ & Depth of cut $(\mathrm{mm})$ & Feed $(\mathrm{mm} / \mathrm{rev})$ & Surface $R_{a}(\mu \mathrm{m})$ & $\operatorname{MRR}\left(\mathrm{mm}^{3} / \mathrm{min}\right)$ \\
\hline 49 & \multirow{4}{*}{13} & 200 & 0.30 & 0.05 & 0.145 & 3000 \\
\hline 50 & & 200 & 0.30 & 0.10 & 0.398 & 6000 \\
\hline 51 & & 200 & 0.30 & 0.15 & 0.955 & 9000 \\
\hline 52 & & 200 & 0.30 & 0.20 & 2.211 & 12000 \\
\hline 53 & \multirow{4}{*}{14} & 200 & 0.60 & 0.05 & 0.265 & 6000 \\
\hline 54 & & 200 & 0.60 & 0.10 & 0.487 & 12000 \\
\hline 55 & & 200 & 0.60 & 0.15 & 0.999 & 18000 \\
\hline 56 & & 200 & 0.60 & 0.20 & 1.999 & 24000 \\
\hline 57 & \multirow{4}{*}{15} & 200 & 0.90 & 0.05 & 0.148 & 9000 \\
\hline 58 & & 200 & 0.90 & 0.10 & 0.477 & 18000 \\
\hline 59 & & 200 & 0.90 & 0.15 & 0.987 & 27000 \\
\hline 60 & & 200 & 0.90 & 0.20 & 2.165 & 36000 \\
\hline 61 & \multirow{4}{*}{16} & 200 & 1.12 & 0.05 & 0.254 & 11200 \\
\hline 62 & & 200 & 1.12 & 0.10 & 0.345 & 22400 \\
\hline 63 & & 200 & 1.12 & 0.15 & 1.115 & 33600 \\
\hline 64 & & 200 & 1.12 & 0.20 & 1.896 & 44800 \\
\hline
\end{tabular}

\section{Conflicts of Interest}

The authors declare that they have no conflicts of interest.

\section{Acknowledgments}

This project was supported by King Saud University, Deanship of Scientific Research, College of Engineering Research Center.

\section{References}

[1] I. Asiltürk, "Predicting surface roughness of hardened AISI 1040 based on cutting parameters using neural networks and multiple regression," International Journal of Advanced Manufacturing Technology, vol. 63, no. 1-4, pp. 249-257, 2012.

[2] R. Mokhtari Homami, A. Fadaei Tehrani, H. Mirzadeh, B. Movahedi, and F. Azimifar, "Optimization of turning process using artificial intelligence technology," International Journal of Advanced Manufacturing Technology, vol. 70, no. 5-8, pp. 1205-1217, 2014.

[3] F. Jafarian, M. Taghipour, and H. Amirabadi, "Application of artificial neural network and optimization algorithms for optimizing surface roughness, tool life and cutting forces in turning operation," Journal of Mechanical Science and Technology, vol. 27, no. 5, pp. 1469-1477, 2013.

[4] Y. Karpat and T. Özel, "Multi-objective optimization for turning processes using neural network modeling and dynamic-neighborhood particle swarm optimization," International Journal of Advanced Manufacturing Technology, vol. 35, no. 3-4, pp. 234-247, 2007.

[5] C. Natarajan, S. Muthu, and P. Karuppuswamy, "Prediction and analysis of surface roughness characteristics of a nonferrous material using ANN in CNC turning," International Journal of Advanced Manufacturing Technology, vol. 57, no. 9-12, pp. 1043-1051, 2011.

[6] F. J. Pontes, A. P. D. Paiva, P. P. Balestrassi, J. R. Ferreira, and M. B. D. Silva, "Optimization of Radial Basis Function neural network employed for prediction of surface roughness in hard turning process using Taguchi's orthogonal arrays," Expert Systems with Applications, vol. 39, no. 9, pp. 7776-7787, 2012.

[7] K. S. Sangwan, S. Saxena, and G. Kant, "Optimization of machining parameters to minimize surface roughness using integrated ANN-GA approach," Procedia CIRP, vol. 29, pp. 305-310, 2015.

[8] G. M. A. Acayaba and P. M. D. Escalona, "Prediction of surface roughness in low speed turning of AISI316 austenitic stainless steel," CIRP Journal of Manufacturing Science and Technology, vol. 11, pp. 62-67, 2015.

[9] D. Bajić, B. Lela, and G. Cukor, "Examination and modelling of the influence of cutting parameters on the cutting force and the surface roughness in longitudinal turning," Strojniski Vestnik/Journal of Mechanical Engineering, vol. 54, no. 5, pp. 322-333, 2008.

[10] A. K. Gupta, S. C. Guntuku, R. K. Desu, and A. Balu, "Optimisation of turning parameters by integrating genetic algorithm with support vector regression and artificial neural networks," International Journal of Advanced Manufacturing Technology, vol. 77, no. 1-4, pp. 331-339, 2015.

[11] A. T. Abbas, M. Alata, A. E. Ragab, M. M. El Rayes, and E. A. El Danaf, "Prediction model of cutting parameters for turning high strength steel grade-H: comparative study of regression model versus ANFIS," Advances in Materials Science and Engineering, vol. 2017, Article ID 2759020, 12 pages, 2017.

[12] A. T. Abbas, D. Y. Pimenov, I. N. Erdakov, T. Mikolajczyk, E. A. El Danaf, and M. A. Taha, "Minimization of turning time for high-strength steel with a given surface roughness using the Edgeworth-Pareto optimization method," International Journal of Advanced Manufacturing Technology, vol. 93, pp. 2375-2392, 2017.

[13] Y. Yamane, T. Ryutaro, S. Tadanori, I. Martinez Ramirez, and Y. Keijiaa Hiroshim, "A new quantitative evaluation for characteristic of surface roughness in turningYasuo," Precision Engineering, vol. 50, pp. 20-26, 2017.

[14] D. M. D'Addona and S. J. Raykar, "Analysis of surface roughness in hard turning using wiper insert geometry," Procedia CIRP, vol. 41, pp. 841-846, 2016.

[15] Z. Pu, J. C. Outeiro, A. C. Batista, O. W. Dillon, D. A. Puleo, and I. S. Jawahir, "Enhanced surface integrity of AZ31B Mg alloy by cryogenic machining towards improved functional 
performance of machined components," International Journal of Machine Tools and Manufacture, vol. 56, pp. 17-27, 2012.

[16] N. Tomac, K. Tonnessen, and F. O. Rasch, "Formation of flank build-up in cutting magnesium alloys," CIRP AnnalsManufacturing Technology, vol. 40, no. 1, pp. 79-82, 1991.

[17] H. K. Tönshoff and J. Winkler, "The influence of tool coatings in machining of magnesium," Surface and Coatings Technology, vol. 94-95, pp. 610-616, 1997.

[18] N. Wojtowicz, I. Danis, F. Monies, P. Lamesle, and R. Chieragati, "The influence of cutting conditions on surface integrity of a wrought magnesium alloy," Procedia Engineering, vol. 63, pp. 20-28, 2013.

[19] E. A. Al Bahkali, A. E. Ragab, E. A. El Danaf, and A. T. Abbas, "An investigation of optimum cutting conditions in turning nodular cast iron using carbide inserts with different nose radius," Proceedings of the Institution of Mechanical Engineers, Part B: Journal of Engineering Manufacture, vol. 230, no. 9, pp. 1584-1591, 2016. 


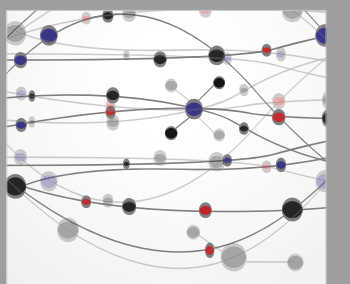

The Scientific World Journal
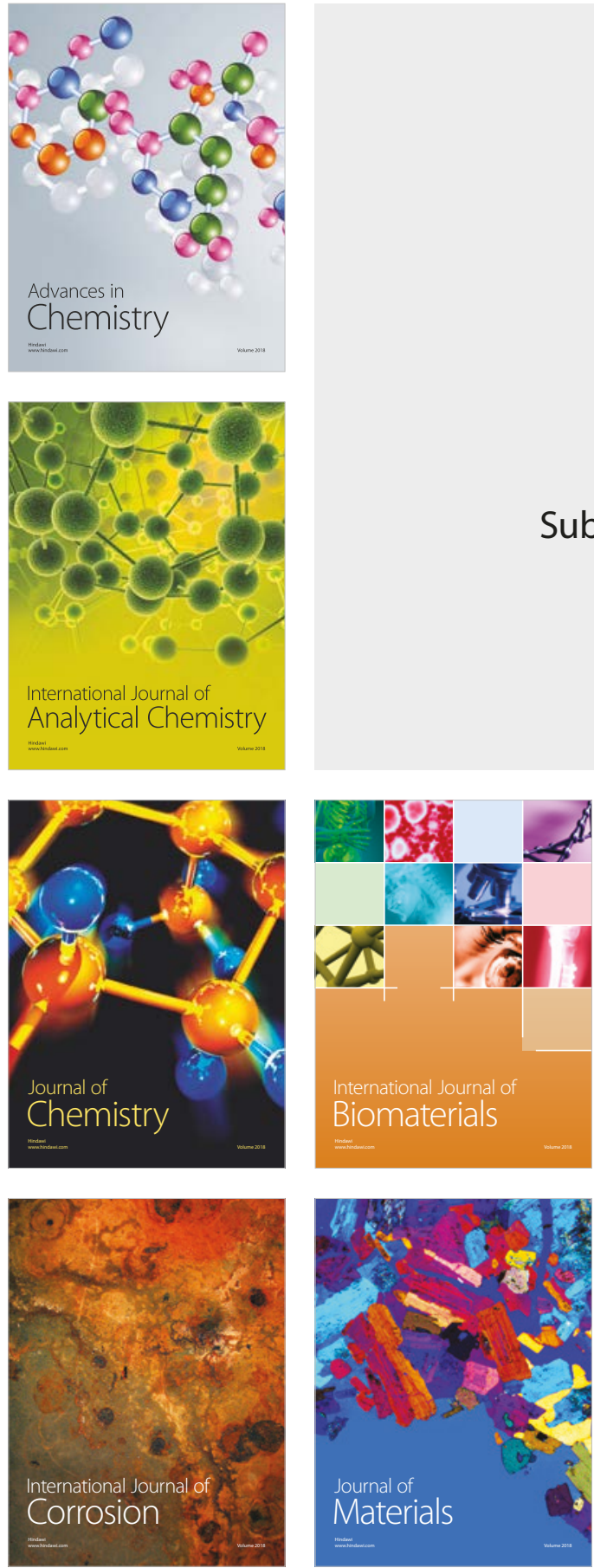

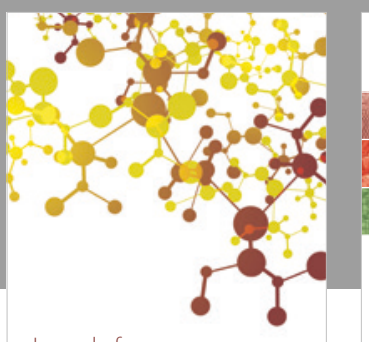

Journal of

Applied Chemistry
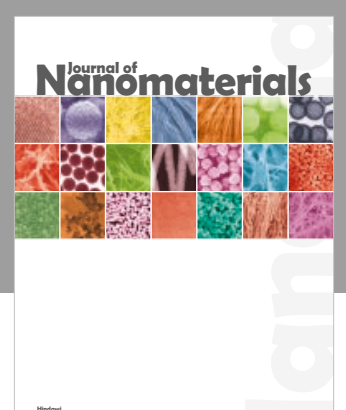

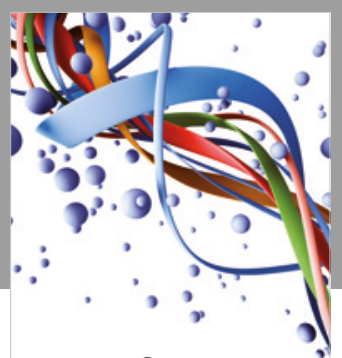

Scientifica

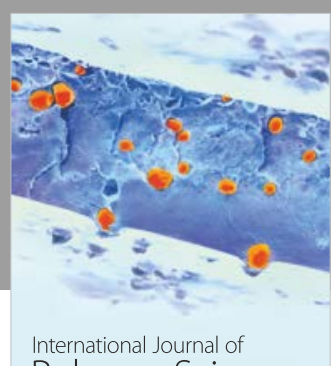

Polymer Science

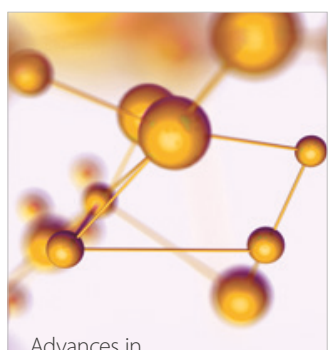

Physical Chemistry
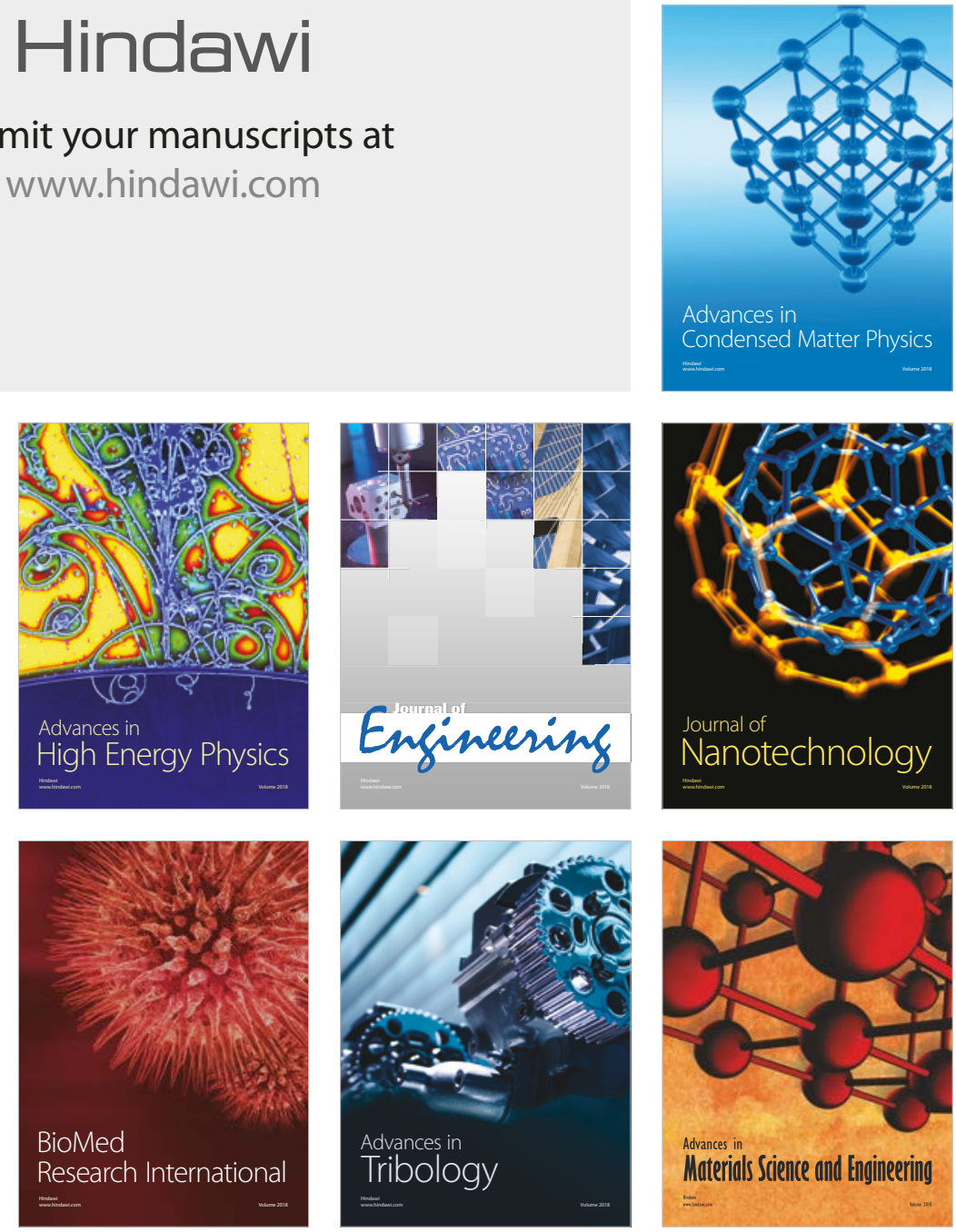